УДК 339.924

О сотрудничестве с Болгарией в сфере науки и образования

\author{
Puдигер A. B. \\ кандидат технических наук, директор, ФГБНУ Государственный центр \\ «Интерфизика», Москва, Россия, 1310@mail.ru
}

\begin{abstract}
Аннотация. Статья посвящена анализу текущего состояния международного сотрудничества Россия - Болгария в области науки и образования. Научно-образовательное сотрудничество России и Болгарии имеет важное значение для Российской Федерации, кроме того Болгария является членом Международного центра научной и технической информации с 1969 г. В этой связи представляет интерес изложить материалы проведенного в 2019 г. мониторинга научно-образовательного сотрудничества с Болгарией, дополнив последние результатами анализа актуальных документов 2020-2021 гг.
\end{abstract}

Ключевые слова: международное научное сотрудничество, международное образовательное сотрудничество, мониторинг, подготовка кадров, Болгария, международные мероприятия, Рабочая группа по вопросам образования и науки.

\title{
About Cooperation with Bulgaria in Science and Education
}

Ridiger A.V.

Federal state-financed organization State Centre «Interphysica», Moscow, Russia,1310@mail.ru

Abstract. The article is dedicated to the analysis of the current state of international cooperation Russia - Bulgaria in the field of science and education. Scientific and educational cooperation between Russia and Bulgaria is important for the Russian Federation, in addition, Bulgaria is a member of the International Center for Scientific and Technical Information from 1969. In this regard, it is interesting to present the materials of the monitoring of scientific and educational cooperation with Bulgaria in 2019, supplementing the latter with the results of the analysis of current documents 2020-2021.

Keywords: international scientific cooperation, international educational cooperation, monitoring, training, Bulgaria, international events, Working Group on Education and Science.

\section{$((c))$ BY}

DOI: 10.31432/1994-2443-2021-16-4-26-36 
Цитирование публикации: Ридигер А.В. О сотрудничестве с Болгарией в сфере науки и образования // Информация и инновации. 2021, Т. 16, № 4. с. 26-36. DOI: 10.31432/1994-2443-2021-16-4-26-36.

Citation: Ridiger A.V. About cooperation with Bulgaria in science and education // Information and Innovations 2021, T. 16, № 4. pp. 26-36. DOI: 10.31432/1994-24432021-16-4-26-36.

Научно-образовательное сотрудничество России и Болгарии имеет важное значение для Российской Федерации [1]. Правовым основанием для международного научно-образовательного сотрудничества с Болгарией является Программа сотрудничества в области культуры, образования и науки между Правительством Российской Федерации и Правительством Республики Болгарии на 2012-2014 годы (далее - Программа) [2]. В связи с завершением срока действия вышеуказанного документа реализуются процедуры внутригосударственного согласования нового проекта Программы сотрудничества в области в области культуры, образования науки между Правительством Республики Болгария и Правительством Российской Федерации.

В целях реализации Программы и координации усилий в области российско-болгарского научно-технического сотрудничества создана российско-болгарская Рабочая группа по вопросам образования и науки (далее - Рабочая группа). В 2018 году проведено заседание Рабочей группы в рамках Международной технической ярмарки в г. Пловдив (Болгария), тогда же прорабатывалось решение об объединении российско-болгарских рабочих групп по образованию и научно-техническому сотрудничеству с сохранением функционала и актуализацией состава с обеих сторон. 27 апреля 2019 г. в Софии состоялось заседание вышеуказанной Рабочей группы, в рамках которого рассмотрены вопросы актуализации проекта Программы сотрудничества в области культуры, образования и науки между Правительством Российской Федерации и Правительством Республики Болгария на 20182020 годы (далее - Программа). К сентябрю 2020 г. было завершено межведомственное согласование Программы (участвовали Минобрнауки России, МИД России, МВД России, Минпросвещения России), в ходе которого согласованы положения, по которым первоначально имели место разногласия: сроки действия и порядок продления Программы, механизмы содействия России развитию болгарских воскресных школ в России а также, русских школ в Болгарии (в частности, средней общеобразовательной школы им. Ю. Гагарина в г. Варна), вопрос открытия представительства образовательного центра «Сириус» на территории СОК «Камчиа», вопрос проведения возможности проведения выставки ведущих российских университетов на территории Болгарии.

25 сентября 2020 г. прошло очередное заседание рабочей группы, а также осуществлены двусторонние консультации по проекту Программы сотрудничества [3]. 
Кроме отсутствия консенсуса по п. 20 программы (право членов семей сотрудников дипломатических и консульских представительств бесплатно обучаться в общеобразовательных организациях государства пребывания, а также по программам среднего профессионального образования и высшего образования в государственных образовательных организациях высшего образования государства пребывания по всем специальностям кроме связанных с медициной, искусством и спортом), по мнению Минобрнауки России не согласован вопрос юридического статуса Программы (либо как межгосударственного договора, либо межведомственной программы) [4]. Для решения данной проблемы предлагается обеспечить участие в заседаниях рабочей группы представителей МИД Болгарии и России.

16 октября 2020 г. проведено очередное заседание Рабочей группы, в ходе которого стороны пришли к консенсусу по поводу проекта Программы сотрудничества в области культуры, образования и науки между Правительством Российской Федерации и Правительством Республики Болгария, который был направлен на рассмотрение и согласование в Министерство образования и науки Республики Болгария [5], Посольство Республики Болгарии в г. Москва [6]. В результате проведения мероприятия было принято решение, что Министерство образования и науки Республики Болгария совместно с Министерством иностранных дел Республики Болгария по получению от Российской стороны соответствующего запроса проведет согласование доработанного текста проекта Программы, а также рассмотрит вопрос о его правовом статусе (в качестве межправительственной программы, либо международного договора, подлежащего ратификации в установленном национальном законодательством Сторон порядке) [7].

Болгарской стороной проведена доработка текста проекта программы, результаты данной работы были переданы в Минобрнауки России, которое, в свою очередь, провело внутриведомственное согласование предложений болгарской стороны к проекту Программы и направило болгарским партнерам текст указанного документа, доработанного с учетом, ранее представленных замечаний [8].

К августу 2021 г. все внутригосударственные согласования проекта российско-болгарской программы сотрудничества в области образования и науки были завершены. В МИД России был направлен проект распоряжения Правительства Российской Федерации «О подписании Программы сотрудничества в области культуры, образования и науки между Правительством Российской Федерации и Правительством Республики Болгарии» [9].

Подписание данных документов даст новый импульс российско-болгарскому сотрудничеству.

Разработанная программа сотрудничества регулирует совместные усилия двух стран, направленные на:

- содействие в установлении прямых партнерских связей между научными и образовательными организациями Российской Федерации и Республики 
Болгарии по вопросам научной и (или) научно-технической, образовательной деятельности; обмена обучающимися, научными, научно-педагогическими, педагогическими и иными работниками; разработки и реализации совместных научно-исследовательских и научно-технических, образовательных проектов, а также научных и образовательных программ в соответствующих сферах;

- содействие участию научных работников и научных организаций сторон в симпозиумах, конференциях и других научных мероприятиях, а также сотрудничеству в совместных научных проектах;

- содействие реализации многосторонних программ по развитию научных исследований и технологий в целях повышения эффективности взаимодействия научных организаций Российской Федерации и Республики Болгария;

- участие в двусторонних и многосторонних программах и проектах в области образования;

- обмен информацией о системах образования обоих государств;

- содействие изучению и преподаванию болгарского языка и литературы, болгарской истории и культуры в образовательных организациях Российской Федерации и русского языка и литературы, русской истории и культурыв образовательных организациях Республики Болгарии, в том числе путем оказания поддержки российским центрам изучения болгарского языка и болгарской сети базовых школ обучения русскому языку и обмена опытом обучающимися и специалистами по вопросам, касаю- щимся контрольно-измерительных материалов для обучения русскому языку как иностранному и болгарскому языку как иностранному;

- поощрение иных форм сотрудничества в области науки и образования на взаимовыгодной основе;

- обеспечение продолжения обучения в российских и болгарских образовательных организациях, обучающихся в рамках межправительственных и межведомственных международных договоров между Российской Федерацией и Республикой Болгарией, на предварительно согласованных условиях.

В рамках Рабочей группы было принято решение разработать межведомственный меморандум о взаимопонимании и сотрудничестве в целях регулирования вопросов российско-болгарского сотрудничества в области образования и науки, в частности вопроса о взаимном признании документов об образовании и ученых степенях. Кроме того, стороны приняли к сведению информацию представителей РАН И РФФИ о состоянии и перспективах российско-болгарского сотрудничества в области фундаментальных науки и участии болгарских ученых в конкурсах РФФИ и намерениях РАН возобновить договоренности с болгарскими партнерами с целью дальнейшего развития научного сотрудничества.

По линии российско-болгарского научно-технического сотрудничества реализуются следующие проекты:

- Минобрнауки России оказывает содействие российским университетам, научным организациям и бизнесу в сфере инноваций; 
- Минобрнауки России ежегодно (с 2016 г.) направляет приглашения болгарской стороне на Московский международный салон образования и форум «Открытые инновации»;

- Минобрнауки России совместно с Россотрудничеством и заинтересованными образовательными организациями проводит работу по реализации Единой дорожной карты по работе в сфере поддержки и продвижения русского языка в Болгарии;

- Осуществляется набор болгарских граждан и российских соотечественников на обучение в вузах России за счет средств федерального бюджета в рамках установленной Правительством Российской Федерации квоты (всего в 2017/2018 учебном году обучалось 281 чел., из них за счет средств федерального бюджета 227, в 2018/2019 году - 295 чел., из них за счет средств федерального бюджета 239; в 2017/2018 году в России обучалось 34 болгарских аспиранта (за счет средств федерального бюджета 30) и 83 слушателя подготовительных факультетов).

За счет средств федерального проекта «Экспорт образования» национального проекта «Образование» функционирует, созданный в 2019 году на базе Средней общеобразовательной школы имени Ю. Гагарина в СОК «Камчия» ресурсный центр экспорта российских образовательных услуг [10]. В целях развития российско-болгарского сотрудничества сформирован консорциум из 7 российских университетов: Российский университет дружбы народов, Национальный исследовательский ядерный университет «МИФИ», Санкт-Петербургский по- литехнический университет им. Петра Великого, Национальный исследовательский университет «МЭИ», Алтайский государственный университет, Московский физико-технический институт, Российская академия народного хозяйства и государственной службы при Президенте Российской Федерации. Задачами центра, деятельность которого курируется Российским университетом дружбы народов, является: привлечение и подготовка иностранных абитуриентов для обучения в российских университетах, реализация образовательных программ по профильным предметам, обеспечение методического сопровождения проекта через проведение различных мероприятий для целевой аудитории (семинаров, мастер-классов, конференций и т.п.).

Деятельность в области российско-болгарского научно-образовательного сотрудничества также координируется в рамках Межправительственной Российско-Болгарской комиссии по экономическому и научно-техническому сотрудничеству, заседания которой происходят на регулярной основе. Реализация договоренностей, достигнутых в ходе заседаний комиссии, контролируется Правительством Российской Федерации (головной федеральный орган исполнительной власти - Минэкономразвития России) [2].

Проведенный анализ показывает, что Российско-болгарское сотрудничество по линии образования развивается в основном с нисходящим трендом. На 2020/2021 учебный год выделено 140 мест для обучения граждан Республики Болгария в России (имеется канди- 
датов - 172). По сравнению с 2019/2020 учебным годом квота уменьшилась на 90 мест. По состоянию на 1 октября 2020 г. по образовательным программам высшего образования в российских организациях обучалось 328 граждан Республики Болгария, из них 298 граждан - за счет бюджетных ассигнований, 30 чел. обучалось на договорной основе. Численность обучающихся по сравнению с 2019 годом увеличилась на 35 человек, а численность обучающихся на договорной основе упала на 9 человек. На 2018/2019 учебный год план приема иностранных граждан, лиц без гражданства, в т.ч. соотечественников, проживающих за рубежом, на обучение в образовательных организациях Российской Федерации предусматривал квоту для Болгарии - 185 чел.

Тренд снижения подтверждается также данными Центра социального прогнозирования: за 2019 год количество граждан Болгарии, обучающихся в России, сократилось на 88 человек (15\% от уровня 2017/2018 учебного года) [2].

Распределение граждан Республики Болгария в пределах квоты в 2020/2021 учебном году по уровням образования следующие:

Бакалавриат - 87 чел.

Специалитет - 20 чел.

Магистратура - 23 чел.

Аспирантура - 7 чел.

Дополнительное профессиональное образование - 2 чел.

У граждан Болгарии, обучающихся в России, наиболее популярны следующие направления подготовки (указаны 3 специальности в порядке убы- вания количества обучающихся). В 2019 году: русский язык как иностранный, международные отношения, менеджмент; в 2021 году: международные отношения, лечебное дело, менеджмент.

По результатам мониторинга за 2019 г. наибольшее число граждан Болгарии обучались в Российском государственном педагогическом университете им. А.И. Герцена (22 чел.), Государственном институте русского языка им. А.С.Пушкина (20 чел.), Национальном исследовательском университете «Высшая школа экономики» (14 чел.), Российском университете дружбы народов (12 чел.). За 2020 год: в Национальном исследовательском университете «Высшая школа экономики» - 36 чел., Финансовом университете при Правительстве Российской Федерации - 27 чел., Российской академии народного хозяйства и государственной службы при Президенте Российской Федерации - 25 чел. За 2021 год: в Национальном исследовательском университете «Высшая школа экономики» - 16 чел., Санкт-Петербургском государственном университете - 13 чел., Финансовом университете при Правительстве Российской Федерации - 11 чел.

Научно-образовательное сотрудничество с Болгарией осуществляется по следующим направлениям:

- освоение дополнительных профессиональных образовательных программ, в т.ч. стажировки;

- реализация совместных образовательных программ;

- проведение научных исследований.

С болгарской стороны партнерскими организациями выступают: Болгарская 
Академия наук, Болгарский Красный Крест, Варненский университет, 3оологический институт Софии, Медицинский университет Пловдива, Новый Болгарский университет, Общество промышленной и прикладной математики, Общество русистов Болгарии, Пловдивский университет им. Паисия Хилсндарского, Русенский университет имени Ангела Кынчева, Софийский горно-геологический университет им. Св. Ивана Рильского, Софийский технический университет, Софийский университет, Софийский университет им. Св. Климента Охридского, Софийский университет химической технологии и металлургии, Технический университет Софии, Университет «Ангел Канчев», Университет строительства, архитектуры и геодезии Софии, Хозяйственная академия им. Ценова, Экономический университет Варна, Американский университет Болгарии.

С участием представителей ведущих российских университетов Москвы, Санкт-Петербурга, Ростова на Дону и Барнаула в рамках выставки «Время учиться в России», 17-18 декабря 2020 г. проведена серия презентаций и вебинаров об актуальных направлениях подготовки в российских вузах, правилах приема в 2020/2021 учебном году, а также о возможностях, которые дает российское образование.

В рамках реализации Программы продвижения русского языка и образования на русском языке Институт русского языка им. А.С. Пушкина создал портал открытого дистанционного образования «Образование на русском» на котором проходят обучение на русском языке иностранные учащиеся и преподаватели в рамках дистанционных курсов повышения квалификации. По состоянию на декабрь 2020 г. в Болгарии зарегистрировано 772982 просмотра и 63372 уникальных пользователя, курсы повышения квалификации с помощью портала проходят 57 преподавателей из Болгарии.

Научно техническое сотрудничество с Болгарией осуществляется в рамках реализации поручения Правительства Российской Федерации [1], в соответствии с которым Минобрнауки России развивает сотрудничество между российскими и болгарскими научными организациями и институтами развития.

По линии научно-технического сотрудничества Минобрнауки России совместно с Минпромторгом России, Минэнерго России и Торгово-промышленной Палатой России прорабатывался вопрос об участии России в Пловдивской ярмарке (23-28 сентября 2019 г.) в качестве страны-партнера. В данном мероприятии российская делегация участвует ежегодно.

Основным механизмом двустороннего научно-технического сотрудничества является межправительственная комиссия. Кроме того, вопросы научно-технического сотрудничества координируются в рамках рабочей группы по вопросам образовательного и научно-технического сотрудничества.

Научные организации России и Болгарии принимают участие в ежегодных международных мероприятиях, организуемых государственными органами управления в сфере образования и науки России и Болгарии, таких как 
Пловдивская научно-техническая ярмарка, международная выставка «Образование без границ». В мероприятиях традиционно участвуют Российский университет дружбы народов, Национальный исследовательский университет «МИФИ», Российская академия народного хозяйства и государственной службы при Президенте Российской Федерации. Активное сотрудничество с болгарскими партнерами осуществляется по линии Владимирского государственного университета, Института всеобщей истории РАН, Института славяноведения, Академии труда и социальных отношений.

Многостороннее научно-техническое сотрудничество с Болгарией осуществляется в рамках проблемно-тематического плана научно-исследовательских работ и международного сотрудничества Объединенного института ядерных исследований, участником которого с момента учреждения (1956 г.) является Болгария.

Научно-техническое сотрудничество ведется также по линии совместных проектов Российского фонда фундаментальных исследований (РФФИ) и Национального научного фонда Болгарии (ННФБ) [5].

В соответствии с протоколами заседаний Межправительственной российско-болгарской комиссии по экономическому и научно-техническому сотрудничеству РФФИ совместно с ННФБ ведется работа по проведению двусторонних международных конкурсов научных работ. Так, на первый конкурс поступила 91 заявка (81 заявка допущена к экспертизе) по следующим научным направлениям:

- математика, механика и информатика;

- физика и астрономия;

- химия и науки о материалах;

- биология и медицинские науки;

- науки о Земле;

- инфокоммуникационные технологии и вычислительные системы;

- фундаментальные основы инженерных наук.

По итогам конкурса было поддержано 10 проектов с финансированием в течение 2-х лет, грант на проект 700000 рублей, с болгарской стороны равноценное финансирование 25000 лев (проекты со сроком исследований в 2017-2018 гг.).

Учитывая взаимный интерес учёных двух стран к совместному конкурсу, РФФИ-ННФБ было подписано приложение к Меморандуму и объявлен конкурс на 2018 год.

На конкурс 2018 года было подано 120 заявок по следующим научным направлениям:

- математика, механика;

- физика и астрономия;

-химия и науки о материалах;

- биология;

- науки о Земле;

- инфокоммуникационные технологии и вычислительные системы;

- фундаментальные основы инженерных наук;

- история, археология, этнология и антропология, философия, политология, социология, правоведение, социальная история науки и техники, науковедение и экономика; 
- филология и искусствоведение;

- психология, фундаментальные проблемы образования;

- фундаментальные основы сельскохозяйственных наук.

По итогам конкурса было поддержано 20 проектов (срок исполнения проектов - 2 года, финансирование 700000 рублей).

В связи с тем, что российские и болгарские ученыепроявили очень сильнуюзаинтересованность в совместных исследованиях, болгарской стороной было предложено в октябре 2018 года объявить новый конкурс. Было подписано Приложение к Соглашению о сотрудничестве между РФФИ и Национальным научным фондом Болгарии о конкурсе исследовательских российско-болгарских проектов 2019 года. Учитывая динамику постоянного роста сотрудничества обеими сторонами, было принято решение по результатам экспертизы поддержать до 30 проектов.

В 2020 г. Национальным научным фондом Болгарии совместно с РФФИ был объявлен конкурс на реализацию совместных научных проектов, на который поступило 213 заявок от российских и болгарских научных коллективов, в результате проведенных конкурсных процедур было поддержано 33 проекта.

Также следует отметить международные научные связи РАН с болгарскими организациями. В результате сотрудничества Института геохимии и аналитической химии РАН и Института общей и неорганической химии Болгарской академии наук были разработаны высокочувствительные и селективные методы определения рения в рудах и ренийсодержащих материалов с пределом обнаружения до 1 нг/мл и созданы экспресс-тесты, которые используются в геологических экспедициях (Курильская гряда) при поисках сырьевых источников рения.

Следует отметить, что Болгария активно сотрудничает с партнёрами из стран по линии европейских программ и инициатив по развитию научно-технического и инновационного комплекса, в частности, в рамках Рамочной программы ЕС «Горизонт 2020» (участвовали Центр растениеводства и биотехнологий Болгарии, Софийский университет Св. Климента Охридского, Институт молекулярной биологии и биотехнологии, Научно-исследовательский институт овощеводства Марица, Софийский технологический университет). Наиболее активно в рамках программы «Горизонт 2020» болгарские организации сотрудничали с коллегами из Германии, Испании, Великобритании и Италии. Министерство образования и науки Болгарии и Национальный научный фонд Болгарии участвовали в следующих проектах ERA-NET: BiodivERsA3, BiodivScen, CHIST-ERA III, FLAG-ERA II, M-ERA.NET, QuantERA, ERA.Net RUS PLUS. Из них Минобнауки России являлся только участником проекта ERA.Net RUS PLUS, в рамках которого по итогам проведенного в 2017 году конкурса Национальным научным фондом Болгарии было поддержано 4 проекта по следующим направлениям:

- социальные и гуманитарные исследования;

- робототехника;

- нанотехнологии. 
В рамках Федеральной целевой программы «Исследования и разработки по приоритетным направлениям развития научно-технологического и инновационного комплекса России на 2014-2020 годы» совместных двусторонних проектов с Болгарией не реализовывалось.

По данным ведомственной статистики [11] в 2019 г. российскими вузами, подведомственными Минобрнауки России, реализовывалось всего 2 научных проекта с Болгарией, по которым осуществлялось финансирование с Болгарской стороны в форме грантов или контрактов на общую сумму 139200 руб.[12]. В 2020 году таких проектов не было, в то время как в 2016 году общая сумма финансирования со стороны Болгарии совместных проектов составляла 330000 руб.[13].

\section{Выводы}

Проведенный исполнителем анализ показал, что в последние годы фиксируются тенденции по снижению международного образовательного сотрудничества с Болгарией как по линии образовательного сотрудничества, так и по линии научного сотрудничества. Падает количество обучающихся в России граждан Болгарии, выручка российских вузов от грантов и контрактов в рамках международного сотрудничества.

К положительным тенденциям следует отнести завершение работ по подготовке к подписанию Программы сотрудничества в области культуры, образования и науки между Правительством Российской Федерации и Правительством Республики Болгарии.
Следует также отметить отсутствие совместных проектов с Болгарией в области научной и технической информации и очевидную необходимость перенесения усилий российских субъектов международного сотрудничества в область образовательных проектов.

\section{АИТЕРАТУРА}

1. Поручение Правительства Российской Федерации от 22 октября 2020 г. № КЧ-П2-9131.

2. О.Н. Гуцынюк. Отчет по теме: «Анализ текущего состояния международного сотрудничества Россия - Венгрия и Россия - Болгария в области науки и разработка предложений по развитию международного сотрудничества с Венгрией и Болгарией, применительно к компетенции МЦНТИ», М: АНО «ЦСИНО», 2019 г.

3. Письмо Минобрнауки России от 18 сентября 2020 г. № МH-12/2205 «О заседании совместной рабочей группы по вопросам образования и науки».

4. Письмо Минобрнауки России от 14 октября 2020 г. № MH-12/2444 «О заседании совместной рабочей группы по сотрудничеству в сфере образования и науки».

5. Письмо Минобрнауки России от 27 ноября 2020 г. № МH-12/2871 «О заседании совместной рабочей группы по сотрудничеству в сфере образования и науки».

6. Письмо Минобрнауки России от 27 ноября 2020 г. № ИН-12/2875 «О протоколе заседания совместной рабочей группы по сотрудничеству в сфере образования и науки и проекте межправительственной программы сотрудничества». 
7. Протокол заседания российско-болгарской Рабочей группы по сотрудничеству в области образования и науки от 16 октября 2020 г.

8. Письмо Минобрнауки России от 21 мая 2021 г. № МH-12/1111 «О межправительственной программе сотрудничества России и Болгарии».

9. Письмо Минобрнауки России от 2 августа 2021 г. № МH-12/776-НБ «О российско-болгарской межправительственной программе сотрудничества».

10. Письмо Минобрнауки Росси от 13 января 2021 г. № МH-12/16 «О реализации решений XVII заседания Российско-Болгарской МПК.

11. Министерство науки и высшего образования Российской Федерации. Отчеты о научной деятельности вузов. Сайт rptnid.ru.

12. Европейская Комиссия/ Проект «Горизонт 2020»/Университет Благоевграда.

13. Университет Софии, АД «Албена».

\section{REFERENCES}

1. Poruchenie Pravitel stva Rossijskoj Federacii ot 22 oktyabrya 2020 g. № KChP2-9131.

2. O.N. Gucynyuk. Otchet po teme: «Analiz tekushhego sostoyaniya mezhdunarodnogo sotrudnichestva Rossiya Vengriya i Rossiya - Bolgariya v oblasti nauki i razrabotka predlozhenij po razvitiyu mezhdunarodnogo sotrudnichestva s Vengriej i Bolgariej, primenitel’no k kompetencii MCzNTI», M: ANO «CzSINO», 2019 g.

3. Pis`mo Minobrnauki Rossii ot 18 sentyabrya 2020 g. № MN-12/2205 «O zasedanii sovmestnoj rabochej gruppy po voprosam obrazovaniya i nauki».
4. Pis`mo Minobrnauki Rossii ot 14 oktyabrya 2020 g. № MN-12/2444 «O zasedanii sovmestnoj rabochej gruppy po sotrudnichestvu $v$ sfere obrazovaniya i nauki».

5. Pis`mo Minobrnauki Rossii ot 27 noyabrya 2020 g. № MN-12/2871 «O zasedanii sovmestnoj rabochej gruppy po sotrudnichestvu v sfere obrazovaniya i nauki».

6. Pis`mo Minobrnauki Rossii ot 27 noyabrya 2020 g. № IN-12/2875 «O protokole zasedaniya sovmestnoj rabochej gruppy po sotrudnichestvu $v$ sfere obrazovaniya i nauki i proekte mezhpravitel`stvennoj programmy` sotrudnichestva».

7. Protokol zasedaniya rossijsko-bolgarskoj Rabochej gruppy po sotrudnichestvu v oblasti obrazovaniya i nauki ot 16 oktyabrya $2020 \mathrm{~g}$.

8. Pis`mo Minobrnauki Rossii ot 21 maya 2021 g. № MN-12/1111 «O mezhpravitel`stvennoj programme sotrudnichestva Rossii i Bolgarii».

9. Pis`mo Minobrnauki Rossii ot 2 avgusta 2021 g. № MN-12/776-NB «O rossijsko-bolgarskoj mezhpravitel`stvennoj programme sotrudnichestva».

10. Pis'mo Minobrnauki Rossi ot 13 yanvarya 2021 g. № $\mathrm{MN}-12 / 16$ «O realizacii reshenij XVII zasedaniya Rossijsko-Bolgarskoj MPK.

11. Ministerstvo nauki i vy`sshego obrazovaniya Rossijskoj Federacii. Otchety`o nauchnoj deyatel nosti vuzov. Sajt rptnid. ru.

12. Evropejskaya Komissiya/ Proekt "Gorizont 2020"/Universitet Blagoevgrada.

13. Universitet Sofii, $A D$ «Albena». 